\title{
LEAN CONCEPT - A Challenge To MANagers FOR THE BETTER FUTURE OF THE COMPANY
}

\author{
BOZICKOVIC, R. \& MARIC, B.
}

Abstract: We are on the threshold of joining the European Union (EU) and our business environment is experiencing a severe economic and financial crisis, which is a part of the global crisis. Based on the fact that mental and technological creativity grows just in times of crisis, the Lean concept is gaining recognition and becoming a challenge to future scientists, researchers and entrepreneurs in our country. Inspired by the Japanese automotive industry, it is synonymous with a good way to get out of the crisis. The time of crisis in giving us the best time to develop the strategies of work process improvement and the application of Lean concept. The crisis facilitates the use of new paradigms with completely new mental models in the business of organizational systems. This concept provides a focus on people, their training in work processes, teamwork and continuous improvement. They are crucial for the efficiency level in the use of key resources: people, techniques, property or capital invested in human labour performance. This paper is divided in six parts. The first part deals with general introduction, the second with general principles and tools of Lean concept with stressing the significance of graphic representation of working process. The third part deals with the methodology of introducing the Lean concept. The fourth part deals with research challenges in the field of industrial engineering and management. Conclusions are given in the fifth part and the bibliography in the sixth.

Key words Lean concept, effectiveness, efficiency, graphic tool, layout
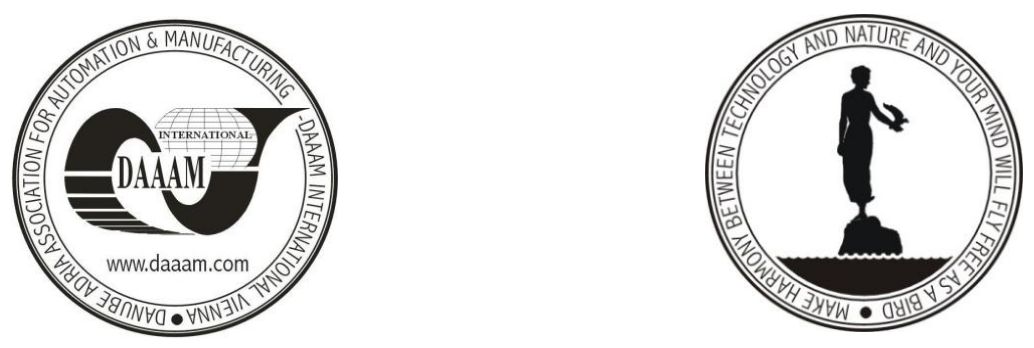

Authors' data: Prof. dr Bozickovic, R[anko]*; Prof. Dr Maric, B[ogdan]**, * University of East Sarajevo, Faculty of Transport and Traffic Engineering, Vojvode Mišića 52, Doboj, BiH,** University of East Sarajevo, Faculty of Mechanical Engineering, East Sarajevo, rankob@teol.net, maricbogdan@gmail.com

This Publication has to be referred as: Bozickovic, $\mathrm{R}$ [anko] \& Maric, B[ogdan] (2013) Lean Concept - a Challenge to Managers for the Better Future of the Company, Chapter 27 in DAAAM International Scientific Book 2013, pp. 491-510, B. Katalinic \& Z. Tekic (Eds.), Published by DAAAM International, ISBN 978-3901509-94-0, ISSN 1726-9687, Vienna, Austria

DOI: $10.2507 /$ daaam.scibook.2013.27 


\section{Introduction}

We live in a time of crisis and economic recession when all companies, of all sizes and shapes, from industrial giants, medium and small enterprises, to the microorganization of companies, are faced with challenges to their own survival. In these difficult and complex times of recession and financial crisis, the usual actions of management in leading a company are to reduce costs and waste in all its forms. Therefore, company managers do not usually choose new business programs nor accelerate programs that are under development.

Major changes in the management have resulted from the crisis, affected by large and developed countries, modern scientific and technological progress in the field of computer science, new technologies, new materials, energy development, and communication development, directly influencing each company. Thus, we can no longer talk about running business under stable conditions for a long period of time, but the business in terms of constant changes.

Today's management structure and managers should first know how the company generates profit and then redesign those activities. Toyota's struggle for survival has resulted in the discovery of appropriate programs, principles, methods and tools for the implementation of the lean concept. Recently, during the crisis, the Lean concept has become the philosophy of efficient business and has increased the interest of businessmen and scientists in the processes of its introduction and implementation. Through systematic and continuous Lean programs and establishment of business under the lean environment conditions, we achieve: flexibility and willingness to start production to the demands of customers - the market; better utilization of space resources - layout; better utilization of human resources; continuous increase of knowledge and understanding; the change of the organizational culture and faster identification of workers with work processes and the company and so on.

In times of crisis, Lean implies abandoning the reactive management style in which time is spent dealing with emergencies and it totally accepts the proactive management style in which all available time is devoted to solving the root causes of the inefficiency of systems and processes. It takes a lot of effort for an enterprise to become Lean - long-term, flexible and vital in providing the customer with the full value of products or services. The customer wants the product or service with the highest efficiency, lowest cost of procurement and maintenance during exploitation. It is necessary to establish a continuous process of constant systemic identification and elimination of unnecessary work processes and business waste, everything that does not represent a value from the customer's perspective. The constant systemic elimination of activities that do not create new or additional value to a product or service is a challenge to the survival of any organizational system. Because of all this, it is becoming a challenge for human resource management studies, and the lean concept holds all the answers. 


\section{From an Idea to Lean Concept}

Over the last few decades of the 20th century, lean production as a source of improvement of effectiveness in work processes was getting more and more importance day by day. Lean production has initiated the development of this kind of approach and has generally been a breakthrough into more significant process analyses towards the improvement of production and factory layout in which products are being manufactured. It has changed the way the participants in the work process think and behave and created a state (environment) where the work management is done: the work process, waste elimination in the process of work, constant training of employees at all levels and functions in order to achieve shorter delivery times and cheaper products. In this way, the companies create an environment that represents the lean concept or doctrine in the way of organizing and managing businesses.

In the late 1980's, the Massachusetts Technology Institute (MIT) studied the International Program on motor vehicles. In this research, it analysed automakers comparing the United States, Europe and Japan. The book "The Machine that Changed the World" (Womack, Jones and Roos, 1990) was based on this project. It practically presented the term 'lean manufacturing' in America. The authors concluded that in Japan, streamline processes and ways of organizing production systems were credited for its success. They found that a mixed system based on keeping minimum stocks and maintaining high quality was the basis for the success of Japanese manufacturers, particularly Toyota. Babson (1995) noted that there are similarities with TQM, although many analysts had already pointed to it. Even though they popularized the term "lean" to describe the Toyota production system, authors of the MIT study initially presented many of these ideas to the West. In fact, many books written before Womack's represented different characteristics of the concept. For example, Ohno, Japanese architect of the Toyota production system, wrote "Toyota Production System: Beyond Large-Scale Production" (1978); Shingoe's Study of Toyota production system from the perspective of industrial engineering (1983); Goldrat and Cox published the first edition of "The Goal" (1984); Schonberger wrote "World Class Manufacturing" (1986) and so on. However, the book "The Machine that Changed the World" was very popular with executives and highly sought after document for lean production systems. Another book written by authors Womack and Jones, "Lean thinking" (1996), offered an alternative way of applying lean production. It deals with companies outside the automotive sector which have successfully implemented this principle.

Lean manufacturing in industrial systems (William M. Feld, 2000) is based mainly on designing efficient and effective operation of manufacturing processes that are applicable, flexible, consistent and sustainable in time and space. The labour force was foreseeable and entrepreneurial. Lean production creates a system based on real customer's needs and continuous improvements in all work processes. In this way, the labour force is being developed and trained in the use of lean tools and methods necessary for the achievement of the objective function of the production system and its rise to the world class level. 
Womack argues that the lean concept must be a meaningful concept adopted in the enterprise, in all functions, to see improvement and maintain a system of designed objective functions. A segment or organizational-functional understanding of the application of lean concepts, principles and its actions lead only to a small improvement compared to the effects of comprehensive application.

\subsection{The principles and tools of lean concept}

In their book "Lean Thinking", Womack and Jones (1996) move further from the specific functional approach in the design of production systems and establish the five principles of lean manufacturing: a) Value - focus on customers (the ability or possibility to meet customer's requirements at the right time and for a reasonable price) b) Value stream - effective and efficient work processes (the specific activities necessary for designing, commissioning and provision of certain products from concept to production, from order to delivery, from raw materials to the customer's hands. It is, in fact, the flow encumbrance profile, i.e. process from an idea to finished product to buyers in the market), c) Flow - continuous flow (the full realization of tasks during the "value stream" work process, so that the product passes the process from design to its launch on the market, from order to delivery, from raw materials to customer's hands, without stopping, without scrap, poor quality and without overloading the work process) d) Pull - starting the production to costumer's request (production and delivery of products to customer's request, in which case there will not be any production without their previous request, e) Perfection perfection in work (complete elimination of waste where high values are achieved during the "value stream"). Today, many companies include these principles, but usually only in some of the functions, and less frequently in all functions. These five principles lead the companies to the understanding of the lean approach because their common use of all production system functions can significantly increase production.

To enable the implementation of the whole Lean concept, there is a set of tools (Fig. 1.) which have to be used within the company. Besides the tools shown in the figure, it is possible to create and design other tools that for certain conditions provide better results. If we represent the tools used in the procedures of Lean concept design as a house - a firm creation of human work, and if we should explain the Lean concept as parts of the house, then the supporting pillars would be Just-InTime and Jidoka (or making quality at source).

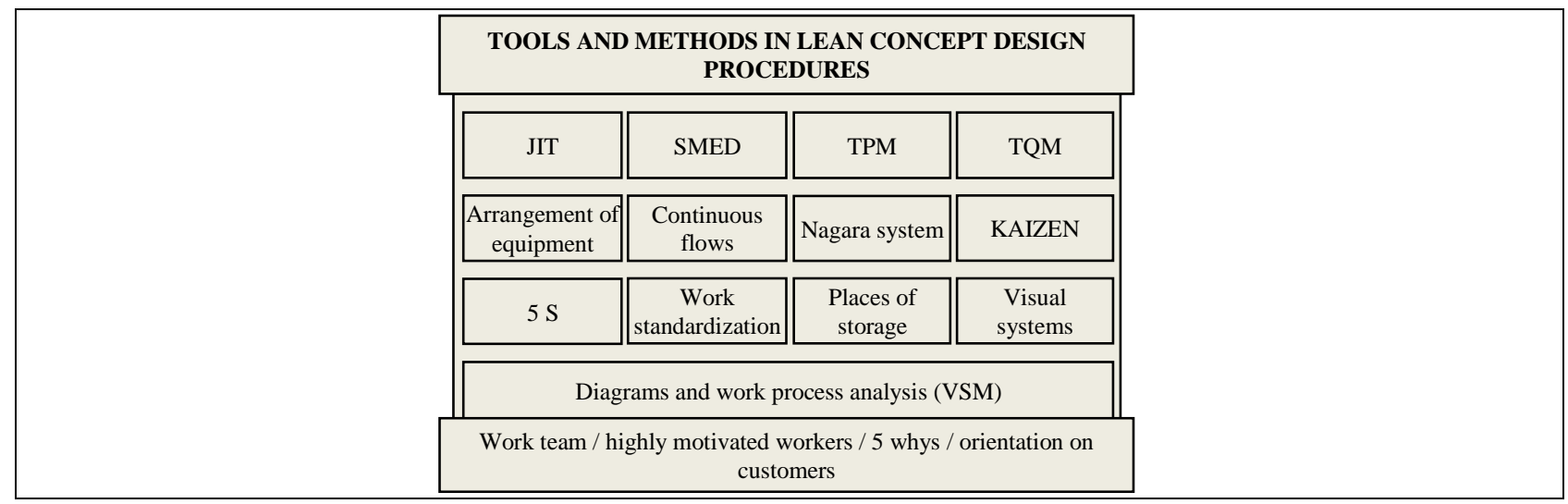

Fig. 1. Tools in Lean concept design 
The foundations of such a house would be Lean philosophy, visual system control, stable and standardized processes, and balanced production. The house would be held by teams through teamwork with the aim of continuous business improvement.

\subsection{Collection and analysis of waste in the flow of materials and information}

Collecting data about work time waste in the flow of materials and information is a very complex process, but the analysis and conclusions are even more complex. Many team members avoid management analysis claiming that they have no time due to operating activities. It usually comes down to the implementation of predetermined plans justified by the deficiencies in the functions of enterprises. In a comprehensive analysis of waste it is necessary to understand the essence of the work processes and activities. Hence, in his study, Japanese architect of the Toyota production system, Ohno, names seven key types of waste in production systems: a) wasteful transport, b) waiting c) excess inventories, d) defects, e) unstable processes, f) unnecessary internal transport, g) overproduction.

One of the lean approach procedures for the reduction and elimination of waste in production systems can be implemented through the following stages: 1) targeting tasks in the production system, 2 graphically representing the state, 3) identifying weak points in the flow, 4) involving customers and suppliers; 5) graphically representing the future state, 6 ) planning benefits via test simulation software (eVSM, SigmaFlow VSM, Simul8, Arena, etc.).

\subsection{The graphical representation of the states in the production system}

The graphs of the work flow state represent a) the current or existing state and b) future states of the system. Many managers do not realize the importance and power of the graphical representation of the work process. However, it is desirable that these charts are updated on a regular basis because graphical representations unconsciously lead those who draw them to the additional suggestion and consultation with many stakeholders in the industry. Some analysts believe that improvised manual procedures are also great encouragements for contemplation as they encourage process designers to think faster in order to eliminate waste.

Until recently, only production supervisors or managers were included in the process. However, many work processes will not be completed unless we involve as many employees in the company as possible. The inclusion of employees is done through teams (work groups). Therefore, the choice of managers and team structure is a starting point for achieving goals in the Lean concept. By the engagement of the top management teams, superiors in the lower hierarchies of organizations are exempted from meetings and often laborious routine work. In this way, they create conditions to complete greater tactical and strategic aims. In order to show the value stream of material and information, a large number of diagrams and symbols are used to create and fill a production flow chart. 


\subsection{Material and information flow charts}

Flow charts can serve as a good starting point for companies that want to introduce the Lean concept. Rother and Shook (1999) represented some views concerning the usefulness of charts: a) they can help in visual representation of the processes in all functions of the production system; b) they can help with identifying losses, their causes and bearers; c) they are a synonym of common language for the discussion on the production process; d) they combine lean tools and procedures in one lean concept; e) they secure basis for the implementation of lean production.

These authors claim that quick and repeated drawing of these charts seems like a cycle of "plan-do-control-adjust" (Deming cycle) that deepens the consideration of creating more efficient and effective work processes. The first step in creating a chart of value flow is the choice of product family as a representative in the spectrum of production and market program of a company. As a representative, one should choose a company that the clients are most interested in at that moment. Some efforts should be made in order to reduce activities that do not enrich the product. It is desirable that all products have these charts ready and that they are updated with the latest improvements. Identification can be done with various methods, the most realistic of which is an $\mathrm{ABC}$ analysis which uses rules and similarities of the shape and the process on the product.

After choosing the product family, the current state is recorded and the current process graphically represented. The physical flow of materials and information are roughly drawn in the chart. It always starts from the processes in connection with the providers and gradually moves towards production preparation, sales, merchandise transport to the buyer, and only in the main flow areas. The next is the analysis and drawing of the processes joining the main flow, i.e. processes in departments and groups. The flow of materials is drawn in the lower part of the chart with every process. All critical information, such as: cycle times, lead times, transport times and stock levels are documented and only the real ones are input in a certain period. The flow of information is drawn in the upper part of the chart. It is drawn from right to left and connected with the previously finished process.

After the chart is completed, a timeline is drawn. It represents a delay at certain stages, whether active or passive. The combination of these times represents, as a rule of thumb, the time from the input of raw materials until the product is delivered. The ultimate goal of this visual chart is fast calculation of the production cycle and delivery time from order to delivery (lead time), as well as noticing activities (jobs) that do not increase the value of the product. Today, flow charts are very successfully supported via software packages eVSM (electronic Value Stream Mapping) or SigmaFlow VSM.

\subsection{Future state charts}

The goal of drawing this chart is to shed light on the points of waste and its causes in order to undertake improvement actions. The future state chart is nothing more than an implementation plan defining the types of lean tools and procedures necessary to eliminate waste noticed in certain places. Creating such a chart is done 
via answering a number of questions regarding the elements of future states, technical implementation, and use of lean tools.

The graphical representation of future states is done after: 1) noticing weaknesses from the graphical representation of the work process state; 2) including the buyer and the deliverer into solving the noticed problem of weaknesses in the whole chain. The graphical representation of the future state is done with the same software tools as the flow chart for materials and information of the current state. In the development stage of the future state chart, simulations of work process can be done with several possible solutions, upon which a decision is made which one to use.

\subsection{Checking the appropriateness of the plan and simulation}

After finishing detailed graphical and other representation of states, we usually come back to the beginning - "goal setting". After that, the team for lean production implementation needs to collect a lot of information. The conclusions based on the information collected are included in the plan of lean production implementation. The next step in forming sub-teams for executing respective part of the plan. However, in order to illustrate the complete procedure, it is necessary to focus again on certain work processes and confirm some vague facts. In many situations, future state charts were done without much effort, and in some other cases it was not easy.

For example, predicting the level of stock throughout the production process is not possible using only the future state chart since the static model cannot be used to envisage the statistical level of stock for various situations (McDonald, 2002). In order to help the organization with applying the lean approach, an additional tool for graphical representation of the value stream is necessary in order to quantify gains during the early planning and estimation. This tool is a simulation able to generate various demands and statistical performances staying flexible with regard to the details of the organization.

The simulation is used in order to reduce unreliability and the dynamic view of investment levels and the use of machines in certain future state, projected in order to create greater effectiveness/efficiency.

The simulation is used to explore the charts of alternative strain on the flows of future states, generated by various answers to the projected questions from the objective functions. It helps organizers and managers with making decision about the variations that yield the best results. It is a level where the greatest results of lean production are expected. The simulation is applicable to specific circumstances of an organization, huge changes in the market, and it can generate demands and performances of the future state with existing or new equipment.

The data obtained via simulation help the management to mark the performances of the designed lean system. Most importantly, the existing system can be changed in the course of introducing designed improvements. 
Bozickovic, R. \& Maric, B.: Lean Concept - a Challenge to Managers for the Bette...

\section{Methodology for Lean Concept Introduction}

II

The methodology for lean concept introduction to production systems consists of five stages divided into two main steps (Figure 2):

A. Project development for lean concept introduction:

Stage 1: preparation for designing the lean concept,

Stage 2: diagnosis of the current state,

Stage 3: design of the lean concept model.

B. Lean concept introduction:

Stage 1: application (introduction) of the lean concept project,

Stage 2: monitoring the application of the designed model.

\subsection{Approach to development of the lean concept project}

Design of a lean concept starts after the management's decision that work processes within systems must be changed in order to achieve greater competitiveness in the market. Its design is a complex process of state analysis and synthesis of those elements into a whole that will bring the greatest benefit to the industrial system. The design procedure consists of the following stages:

The first stage: preparation for designing. This is the stage where as a result of sets of activities we make certain proposals, conclusions and decisions:

- Identification of key losses, errors, problems and guidelines for their solving,

- Defining the terms of reference and their goals,

- Time framework for the completion of all activities,

- The appointment of a team to implement the whole project,

- The decision of management to introduce the lean concept.

In fact, it is the process of assessing the need to switch to the lean concept and determining the current state of the industrial system. States and views on the necessity and importance of the changes must be critically represented. After the changes had been introduced, the next step is to publically present the expected results.

They motivate (drive) employees to pun in greater effort. Motivation, persistence and management of change-inducing processes play a key role in the successful development of the lean concept. If individuals or most employees are not motivated to change, if there are no signs for the next steps after the changes and if, above all, there is no persistence to endure the great challenges in the way of building the lean concept, it is better not to start at all. 


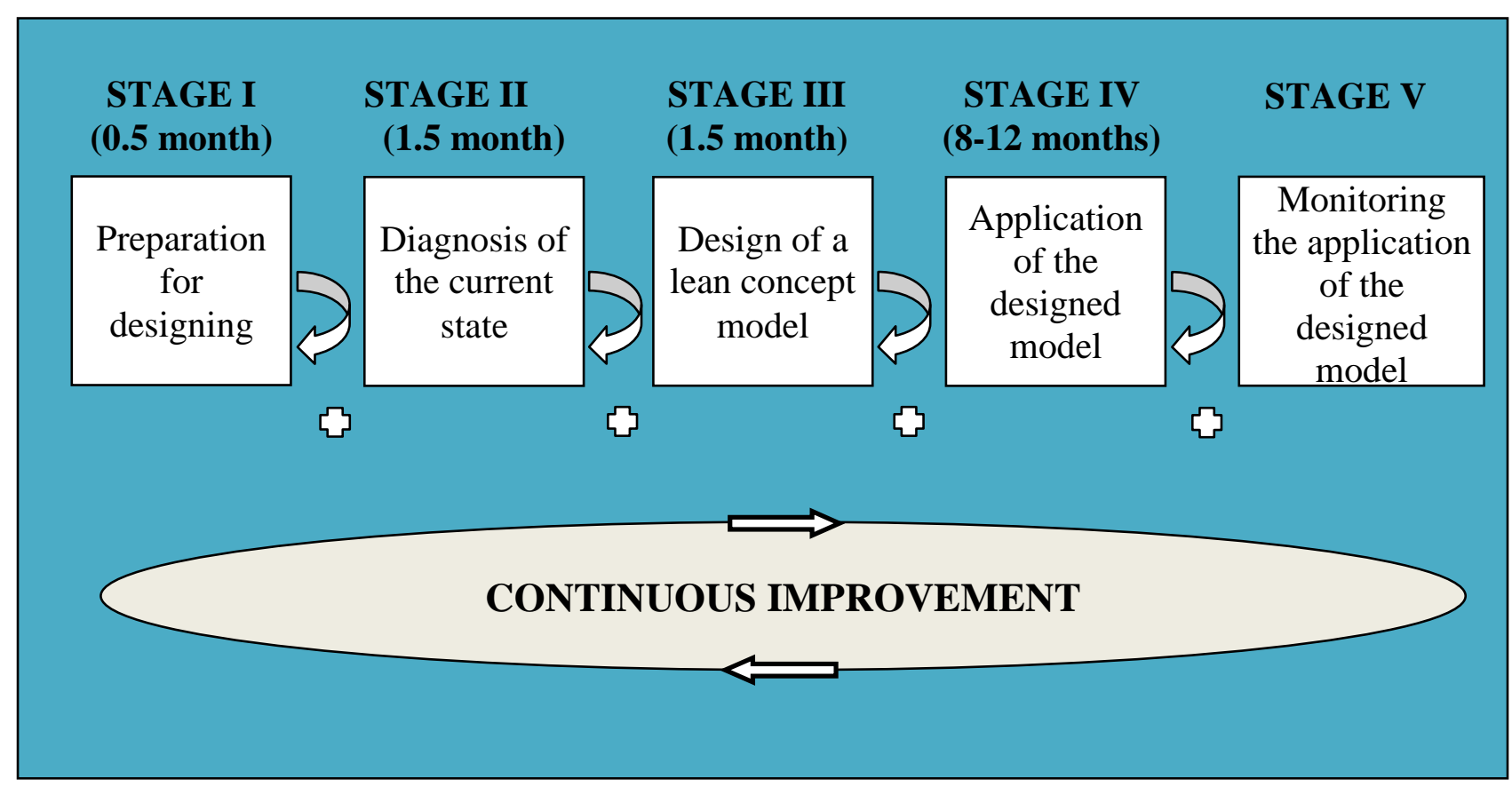

Fig. 2. Required activities for development of the lean concept project

The second stage: diagnosis of the current state. This is the stage in which output documents of the previous stage are used as input, and concrete suggestions and conclusions compiled in a diagnostic study of the current state are considered outputs. This study should include:

- the diagnosis of the application degree of lean principles, methods and tools,

- the possibility of the lean concept implementation,

- the strategy of the lean concept implementation: terms of reference with all proposals and activities and a detailed timetable.

The terms of reference need to define the objectives and results, while the timetable should identify the main stages of the project, the planned deadline for their execution, and many other details related to the realization of the defined framework. The team also need to skilfully use modern information technologies and application software that support the planning and scheduling of the individual stages of the project. Thus, individual project stages or segments can be entrusted to one part of the formed team.

The terms of reference and the timetable should also be accompanied by the following supporting documents (they are considered to be an essential part of good project practice):

- the framework chart of the required steps and work procedures with objective deadlines for implementing the lean concept,

- project protocol (timetable for team meetings, place, duration),

- organization and project team members, 
- established rules and responsibilities,

- ways to identify and address potential risks,

- teamwork rules,

- terms of reference (efficiency indicators, list of financial costs),

- table of results (catalogue of project results, actions, deadlines),

- the team register.

Terms of reference and the timetable created by the team are the first documents of the plan for the lean concept introduction. These documents should be approved and signed by the top management to minimize the risk of failing to carry out the implementation process of such a project. Therefore, the announcement should be represented at all meetings of the industrial system functions.

The third stage: design of the lean concept model. This is the stage where the team from a set of activities creates a study that includes specific variants of the model and financial costs of its implementation. The study should include:

- general assessment of the future economic conditions,

- deficiencies in the existing activities and concepts of loss reduction,

- application of the principles, methods and tools across the lean concept elements (procedures and instructions),

- economic analysis assessments of the application effects of principles, methods and tools,

- the financial plan for the implementation of the whole project.

This stage is the most complex part of the project. Here, the state assessment and observing are done in a more detailed way in order to shape certain models of the lean concept.

The first step: state assessment for lean concept introduction (Figure 3). It is a process of state identification by individual work processes and one by one production program from the standpoint of the lean concept. At this stage, the team should try to identify where the suitable areas and business focal points are. They start by writing a plan that includes methods and contents of work in all elements of the lean concept that improve business.

The team must have the strength to use all five principles of the lean concept in all five of its elements: flows, organization, control, measurements and logistics. In each element, lean principles are analyzed: identifying the value that the customer considers to be important (value), identifying the section of flow loads (value stream), homogeneous flows of materials, information and energy (flow) and process perfection (perfection). 
Elements of the lean concept, principles, methods and tools

3 days

Assessment of possibilities for lean concept implementation

5 days

(the current state of the work process)

Lean concept strategy

(motivation criteria/market division)

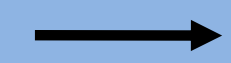

Renorting to management

2 davs

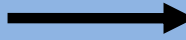

Fig. 3.The first step: The assessment of possibilities for lean concept introduction

The second step: system state recording (Figure 4). The recording provides a basic assessment of where the system is currently. At this step, the team:

- conduct the analysis of the process value,

- analyze the process linking through flows of materials, information and energy,

- make charts of the work process,

- assess where there are opportunities to eliminate wasted time,

- shape the planning criteria to market requirements,

\section{Data collection}

Creating current state charts

(flows of materials, information and energy)

Analysis of loss causes

Reporting to management

Fig. 4. The second step: State recording

- create a sketch of the supply chain (supplier-input-process-output-customer SIPOC), charts of all major work processes to understand the relationship customer/supplier and required inputs and outputs that activate these processes,

- analyze the levels of current losses and errors and perceive opportunities to eliminate what is unnecessary, 
Bozickovic, R. \& Maric, B.: Lean Concept - a Challenge to Managers for the Bette...

- develop a list of quick actions for short-term progress and demonstrate activities that will provide rationalization.

The third step: shaping the future state. This project step begins after the acceptance of the management report on step 2. It is based on shaping the future state that gives greater effects (Figure 5). This process usually takes two to three weeks and includes:

- identifying the groups of products that are profitable and competitive on the market,

- harmonization of system conditions with the project,

- analyzing the range of product requirements and the flow of materials and information,

- team training of employees in the use of tools and methods of the lean concept,

- process development of the new management requirements for the performance of other functions of industrial system in terms of logistics for the lean production.

When the proposal of one part of the project relating to the future state is approved, the team focuses on the other part of this step for another three to four weeks, i.e. the formation of lean concept details. The formation of details includes the following:

- staff plans in all functions across the industrial system,

- presentation of work units in the schedule,

- actions to be performed during the transitional period,

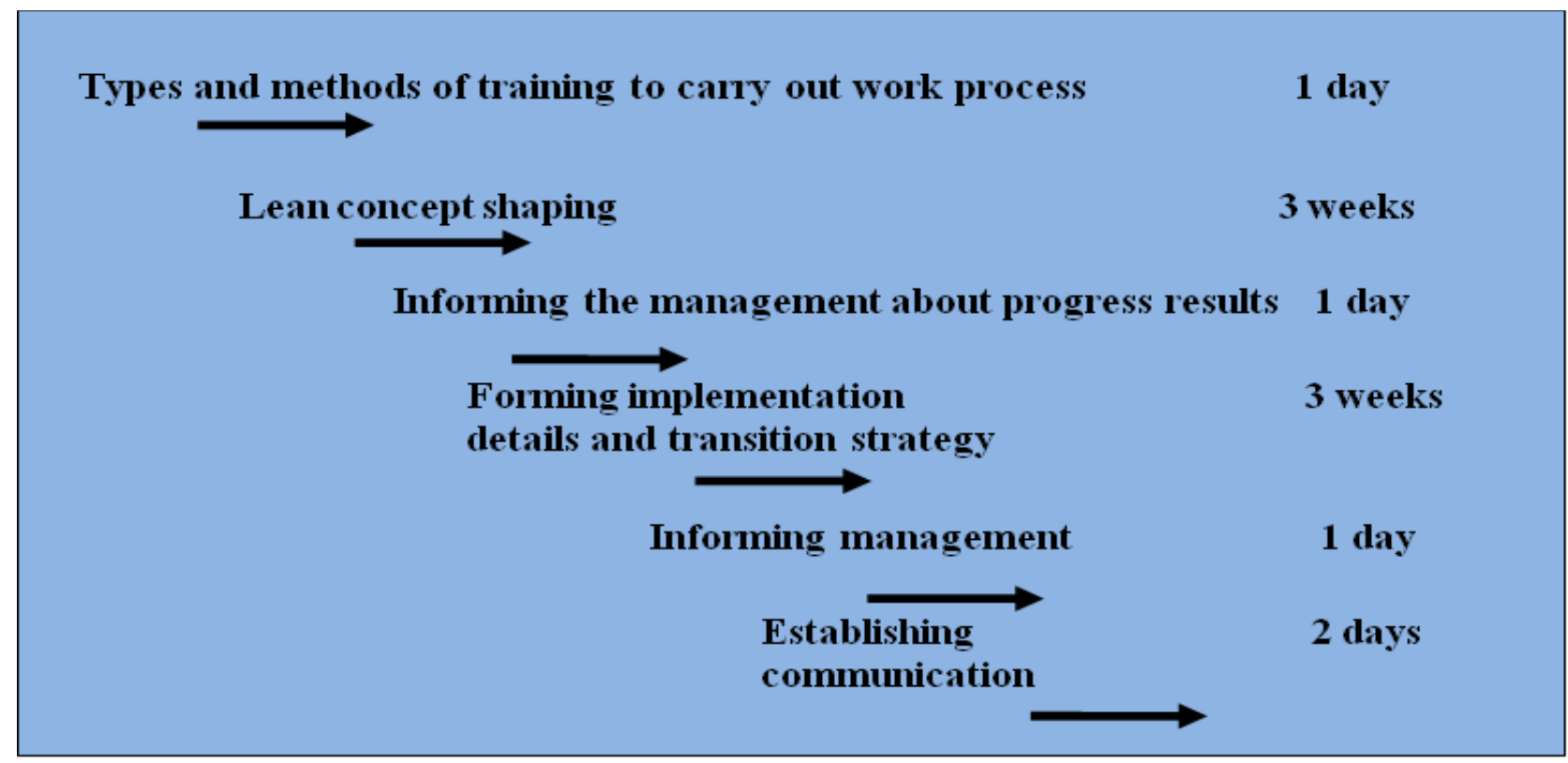

Fig. 5. The third step: Shaping the future state

- the implementation plan of activities with short-term and long-term effects of the planned improvements, 
- the role of layout reconfiguration and accountability for its consistent implementation,

- charts and tables of the effects on notice-boards,

- a plan for training employees to implement the work process,

- a plan of communications in the industrial system.

This plan of the future state is presented to the management for approval. The conversation in terms of plan implementation has to be done with all employees, explaining what was observed, who is involved, what was decided, what the aims of the organization are and what all employees involved in are. At this point the project team reach the fourth step.

The fourth stage: application of the designed model. This is the stage related to the introduction of the lean concept project into the system. It contains the following activities:

- financing the activities defined in the study,

- direct application and the establishment of work process standards to eliminate losses through the principles, methods and tools,

- establishing communication and training of employees,

- measurements and monitoring procedures for the selected characteristics,

- shaping the final work process standards.

\subsection{Lean concept introduction}

The introduction of the lean concept is done after the implementation of the previous stages and steps. The methodology for introduction (implementation) is applied by training the staff in the principles, methods and tools of the lean concept (Figure 6). Its introduction is done by the same teams that created the project.

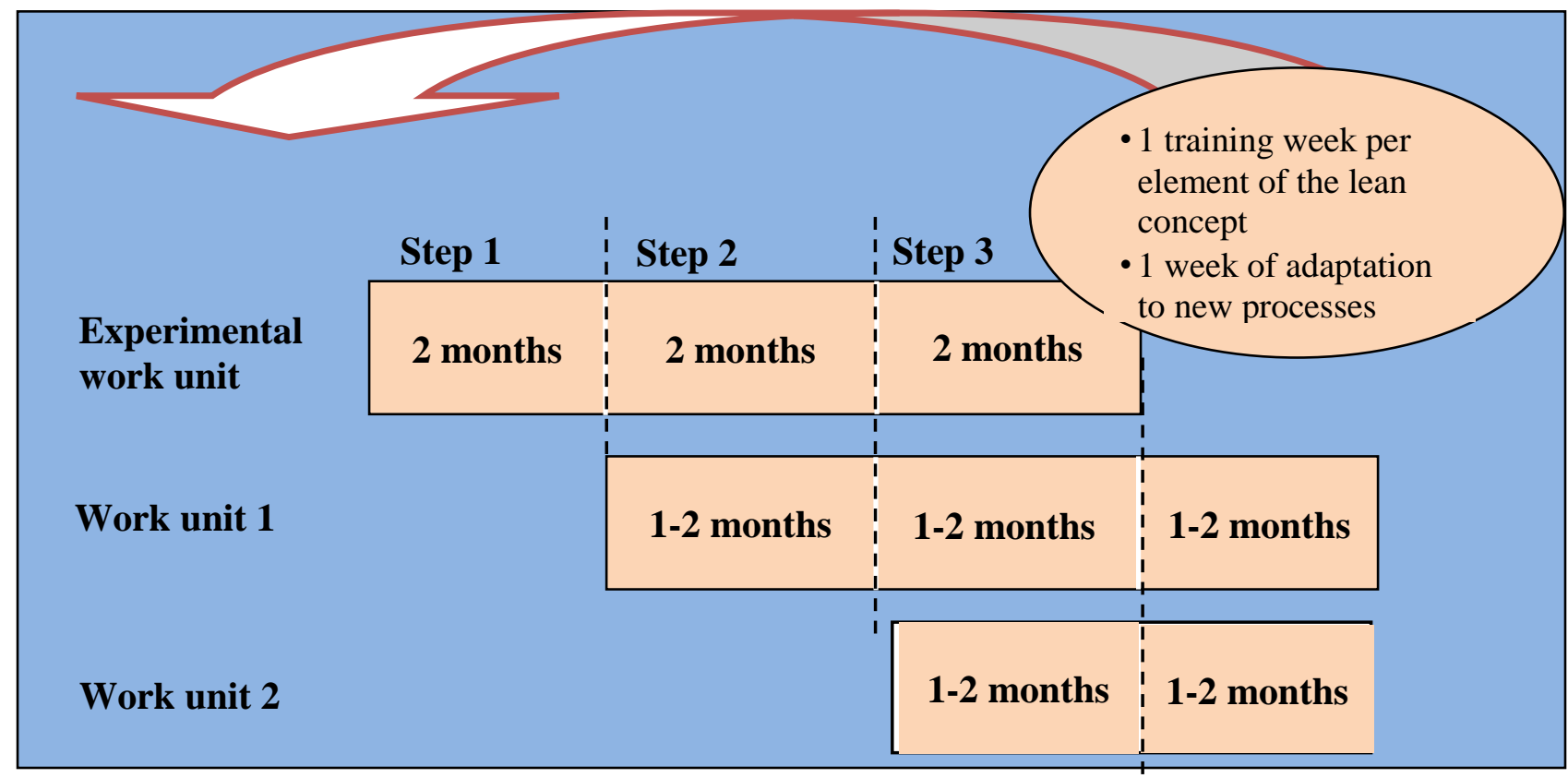

Fig. 6. Methodology for lean concept introduction 
The introduction of the lean concept is conducted through several steps starting from training employees in work units. Framework tools for training by steps are shown in Figure 7. These steps have the role of building blocks and lay the foundation for the later stages. The implementation of the first step includes:

- presentation of material flows within a production system,

- defining the duties of the team, and collective and individual responsibilities,

- shaping the layout of the production system based on the analysis of material, information and energy flows, i.e. based on the adjustment of the work unit to the work process rhythm,

- documenting the contents of work process standardization,

- establishing process, management and control procedures.

After a one-week training of a part of employees, the second week is spent examining the process and creating the conditions for its approval. According to this, it is not possible to complete everything in its final form during the first week. After five to six weeks of training, the process should be stabilized achieving the desired results. Here, the lean concept project should be revised in order to ensure that the implementation is getting the desired characteristics and effects.

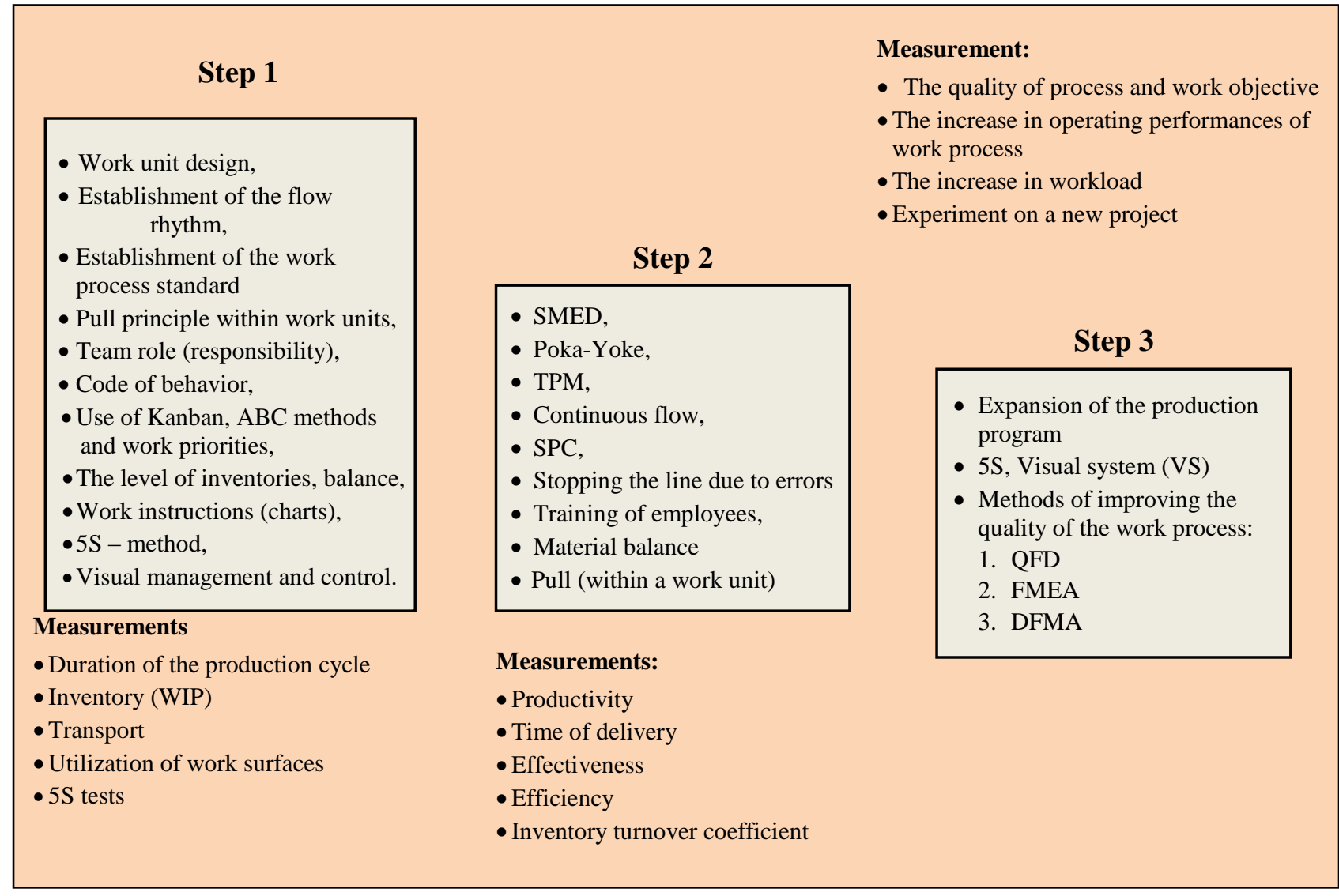

Fig. 7. Framework lean principles, methods and tools for training employees 
When all or most work units have entered the second stage and when they are on their way to self-realization of results, we can proceed to the following business areas:

$\checkmark$ The first area: integration of customers and suppliers in the regulation of more effective and efficient work processes and their participation in planning.

$\checkmark$ The second area: productivity improvements, development of products and new production-technological processes.

$\checkmark$ The third area: business restructuring, i.e. adapting to new market conditions.

$\checkmark$ The fourth area: providing greater confidence in suppliers, i.e. enabling suppliers to perform the assembly of certain subsets.

The fifth stage: monitoring the implementation of the designed project. This is the stage where the team and all employees, each according to their assignments, monitor the implementation of certain characteristics of the work process. These characteristics are compared with those designed and corrections in work are done. The corrections can only be related to the model or the whole concept.

\subsection{Maintaining the lean concept state}

No one would like the changes made by introducing the lean concept to remain static. They must be maintained over time. If they stay unimproved for a long period of time, it means that the industrial system is lagging behind in development. This requires continuous changes: constantly seeking new ways to improve work processes in the name of higher profits. If industrial systems are not improved in the organization or if new technological developments are not followed, they lag behind, lose their value and they are faced with price pressures on the markets. The production of today has to be better than yesterday. Therefore, there is a need to institutionalize changes through the establishment of procedures, such as:

1. It is necessary to develop and apply the checklists of the use of lean methods (e.g., 5-S, SMED, TPM etc.) and have the management systematically review them at least once a month making conclusions.

2. All work processes should be standardized and well learnt with the aim to achieve the highest efficiency and effectiveness.

3. Each team is expected to implement continuous improvement (Kaizen elements).

4. It is necessary to keep record of measurements of all work process characteristics envisaged by the project.

5. Problems in work processes are recorded on the notice-boards and reviewed at the end of each day.

6. Formed teams should have daily briefings in order to review the effects and identify the follow-up tasks.

7. Principles, methods and tools have to be increasingly used for the acquisition of work skills by employees.

8. Equipment should be cleaned and checked every day. 
Bozickovic, R. \& Maric, B.: Lean Concept - a Challenge to Managers for the Bette...

9. Work teams have to visit customers and suppliers and exchange problems at least once in three months.

As a summary of given research, the principle of the lean concept application in industrial systems has been represented in Figure 8. The Figure illustrates the lean concept application in the function of production analyzed through the five elements of the lean concept.

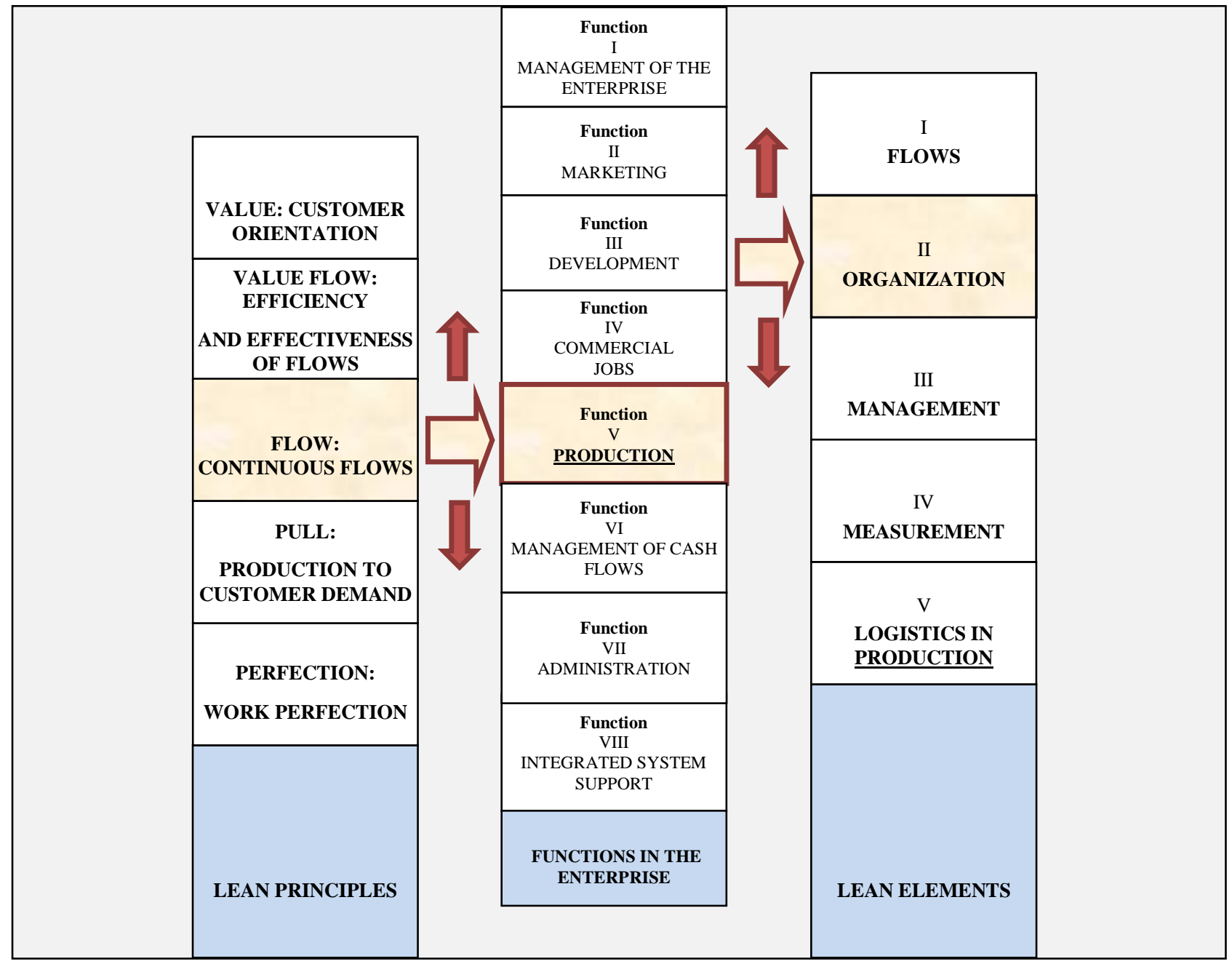

Fig. 8. Lean principles in functions of industrial systems - enterprise

\section{Research Challenges in the field of Industrial Engineering}

The priority of our scientists and researchers in the following years is the contribution to the organizers of the working process in undertaking measures for faster economic recovery and getting out of the economic crisis. Bearing that in mind, the research will be directed towards the managerial and engineering models, methods and tools which will be based on knowledge and innovations. Enabling managers to get their companies to the enviable market competitiveness level, production which is resource efficient and better participation in the labour market are the main determinants and objectives of researchers and economists. Their mutual goal is integration of the national economy into a healthy world economy. , 
The efficient development and operations of the Japanese motor industry still remain a research challenge for the scientists, researchers and economists. It has become the symbol and role model on how to achieve high productivity. This motor industry was created at the time of isolation and general economic embargo of the United States of America and other developed countries toward this country. That is why the researchers and economists worldwide began intensive study of the methods and contents of work and production management in Japan. For a long time the motor industry and the Japanese company Toyota were a role model for many researchers and economists on how to establish and implement technological and organisational efficient.

An architect of Toyota systems, Taiichi Ohno, never imagined that his concept of approach to working process organization would be the subject of research of many economists and scientists. His loss analysis in the working processes became the basis for general work analysis and planning in all the functions of a company.

The world economic crisis annulled some theoretical assumptions on healthy organization of industrial systems, organization of production and production management, as the basis of development of society as a whole. Managing production resources, especially towards the human factor, became harsh with tendencies of maximal use of working process elements. In all this, efficient managerial structure in companies increasingly requires of a man, as a worker in production, to have high skills in the working processes he performs. Therefore, lean production and lean concept become research challenges for scientists in the area of industrial engineering and management. In the future, a person as an organizer and participant will require an interdisciplinary approach to work, no matter where and on which level in the managerial hierarchy or production they might work. Consequently, training managers and employees in companies and industrial systems to use engineering and managerial methods, principles and tools, which can bring about the shift to more efficient business operations, becomes the focus of the research. Managers and employees in companies have to adapt to market changes and change their business and development strategy, organizational structure, and employees in the goal of conquering new skills and knowledge, for their companies to become "lean" and survive in a competitive market.

Mankind is becoming slave to technology and its participation in direct work processes is decreasing. Organizational structures of companies are shaped in such a way to be mutually highly linked by information systems. By working within them, man becomes a mere executor, forced to toil on filing everyday changes in the process of product realization.

Interdisciplinary is demanded from people, organizers and participants, regardless of the level in the management hierarchy or the production line they work on. Educational institutions, even universities, are forced to adapt to what the competition imposes and modern industrial production realizes. Therefore, enabling managers and employees in companies and industrial systems, who are bearers of changes toward more efficient business, is in the focus. According to the opinions of 
the authors of this paper, scientists and researchers in industrial management will turn their interest in the future to the optimization of the work process which brings companies to a higher level of market competition and a faster exit from the crisis. Here, the following is expected:

1. Research on the creation of lean companies and their organizational structures, especially in production and process companies. Research of lean organizational structure will focus on two general cases:

a) companies designed for certain products and

b) companies that are in the phase of adapting to new market conditions, so their reconfiguration is needed.

2. Research on the creation of lean organizational structures of companies in the service sector, such as: transport companies, and companies for servicing and maintaining technical systems. EU development strategy in these areas is directed towards the development of traffic and transport infrastructure, in accordance with which more efficient companies are expected that can follow this development.

3. Research of methodology, methods, principles and tools of lean concept which will efficiently eliminate working time that does not add value to the product and represents loss. The focus will be directed on identifying and separating real losses from inevitable losses in all functions of the organizational system. A description of the analysis and application of lean concept principles through the organizational functions in all lean elements of the working process is illustrated in picture 8 of this paper.

4. Research of methods and work contents on employee skill training on all organizational levels, appropriate for every function or company. Special skills are looked for in managers to recognize measuring indicator of processes, as well as to be trained for efficient visual management and control in all working processes. Here, the role of graphic representation of working processes on fast comprehension and visualization of conditions in the organization system is strongly emphasised. (item 2.3 to 2.5 . of this paper). This will enable efficient and effective lean leaders and workers who participate in the working processes.

5. Research of methodology, procedures and ways of introducing the lean concept, similar to the introduction of ISO standards.

The third chapter of this paper presents one of the general approaches to the introduction of the lean concept. 


\section{Conclusion}

The Lean concept represents a group of efficient and rational procedures in the systematic use of principles, methods and tools in industrial systems on finding and eliminating wasteful activities (losses and errors) in the working processes, thereby creating the necessary conditions for harmonious activities of functions in a company in the given time and in the existing conditions of the environment. Its implementation leads to efficient and effective procedures in working processes which have to be improved, standardized and accepted as models in performing working processes leading to the achievement of high competitiveness and business excellence in work. This contributes to the TQM system by establishing and integrating standard management systems, as well as applying adequate tools for increasing efficiency.

To implement the lean concept in industrial systems, a number of evaluations provided by the management are required. Its implementation depends on people, i.e. the team selected by the management. To make any team successful in its task of developing and introducing the lean concept, the management must answer the following questions:

- Is it possible to hire three to eight people for the period of six to nine months?

- Is it possible to handle failures and mistakes before achieving success and complete the implementation of improved production through the lean concept?

- Is it possible to maintain work team members' participation even when they do not see significant results after two months?

- Is it possible to maintain the engagement of employees in work teams to the final implementation of the project?

- Is it possible to stabilize production in one, two or three weeks?

Additionally, the management should ensure:

- the time required for project implementation,

- funds for the project,

- personnel,

- full-time project team (team focused on the task),

- full performance control of certain stages and steps of the project and approving the following activities of the team.

By establishing the lean concept, the very principles, methods and tools which contribute to efficiency and effectiveness of working processes are being affirmed. It creates a productive climate in industrial systems and a good foundation for further improvements of TQM. The final result is overall satisfaction of employees, users of products or services and society in general. 
Bozickovic, R. \& Maric, B.: Lean Concept - a Challenge to Managers for the Bette...

\section{References}

Božičković, R. (2005). Lean concept in effective production systems; Ph.D. thesis, FTN, Novi Sad.

Božičković, R., Radošević, M., Ćosić, I., Soković, M. \& Rikalović, A. (2012). Integration of Simulation and Lean Tools in Effective Production Systems - Case Study, Strojniški vestnik - Journal of Mechanical Engineering, Vol. 58, No. 11

Božičković, R., Ćosić, I., Božičković, Z. \& Radošević M. (2011). An application of simulation and graphic tools in lean production. $X V$ International Scientific Conference on Industrial Systems (IS'11), Novi Sad, Serbia, September 14 - 16 Ćosić, I. (1983). Contribution to the development of production structures of increased level of flexibility; Ph.D. thesis, FTN, Novi Sad

James, J. \& Frederick, M. (2001). The Lean Company Making the Right Choices, Society of Manufacturing Engineers. International Standard Book Number 0-87263523-6, Dearborn, Michigan.

McDonland, T., Van, E.M. \& Rentes, A.F.; (2002). Utilizing Simulation to Enhance Value Stream Mapping: A Manufacturing Case Application, International Journal of Logistics: Research and Applications, Vol. 5, No. 2, page numbers (213-232)

Rother, M. \& Shook, J.; (1999). Learning to See: Value Stream Mapping to add Value and Eliminate Muda, 1.2 edition, Brookline, MA, The Lean Enterprise Institute Savsar, M. \& Al-Jawini, A.; (1995). Simulation Analysis of JIT Production System, International Journal of Production Economics, Vol. 45,page numbers (101-103)

William M. Feld; (2001). Lean Manufacturing: Tools, Techniques and How To Use Them, The St. Lucie Press / AP; CS Series on Resource Management, International Standard Book Number, 1-57444-297-X, Florida

Zelenović, D., Ćosić, I. \& Maksimović, R. (1998). IIS - Approach to development of effective production structures of industrial systems - enterprises, Sanus, Belgrade. 